\title{
Cardiac workload of dressers in underground manual coal mines
}

\author{
R. Saha, ${ }^{1}$ A Samanta, ${ }^{2}$ N C Dey ${ }^{3}$ \\ ${ }^{1}$ Department of Physiology, National Medical College, Birgunj, Parsa, Nepal; ${ }^{2}$ Department of Occupational Health, \\ Ergonomics and Human Performance Research Laboratory, All India Institute of Hygiene and Public Health (A.I.I.H \&P.H), \\ 110, C.R. Avenue, Kolkata-700073; ${ }^{3}$ Department of Mining Engineering, Bengal Engineering and Science University, Shibpur, \\ P.O: Botanic Garden; Dist: Howrah, Pin: 711103, West Bengal; India
}

Correspondence to: R. Saha, Department of Physiology, National Medical College, Birgunj, Parsa, Nepal

Email: accessrdx@gmail.com

\begin{abstract}
Introduction: Occupational disorders invite absenteeism amongst the miners. Though rapid technological advancement has happened, yet assessment of cardiac workload was largely ignored in underground coal mines in India.

Methods: Physiological stress was evaluated in terms of working heart rate, net cardiac cost and relative cardiac cost. Heart rate was measured during their course of work by heart rate monitor at the coal face. Recovery heart rates and environmental heat load were also assessed.

Results: Heart rate was found to be 117 and 122 beats/min respectively in first and second spell. NCC ( 49.7 and 54.8 beats $/ \mathrm{min}$ ) and RCC (47\% and 52\%) exhibit significant variations between spells, whereas rate of recovery had been very poor amongst the workers who regularly exceeded recommended levels of cardiac strain indices. The nature of work depicted it as a heavy job although recovery trend categorizes it heavier than that. ET and WBGT were above the recommended limits as per the guidelines of WHO and ACGIH.

Conclusions: High physiological demand of the job with towering heat stress was found to hinder the recovery process and may cause deleterious impacts on the workers. Ergonomic interventions were highly felt towards job organization and up gradation of environmental conditions.
\end{abstract}

Keywords: Coalmines, dressers, workload

\section{Introduction}

Hostile and dangerous environment is ineluctable in underground mines and hard manual labours are still very much predominant in Indian coal mines.In addition, miners have to encroach excessive heat, high humidity, vibration, dust etc which makes them prone to a variety of associated health risks. All of these are likely to pose occupational disorders which invites absenteeism. Work physiological studies on coal miners, especially on dressers in India is very scanty therefore the present study was conducted to describe the work methods as well as the cardiac strain experienced by them during the actual situation of work.

\section{Methods}

From three different underground mines of West Bengal,
India, a total of eight dressers who were regular, relatively healthy, had a minimum work experience of five years and were accustomed to work in heat were selected out of 13 . The subjects investigated were less in number since the workers deployed in this category of work had been least in manual coal mines in India. All the subjects agreed to render themselves voluntarily in accordance with the design of the experiment. Extensive interactions were carried out at regular intervals for a period of one month where they were explained about the objective of the study along with their extent of involvement.

Age (years), height $(\mathrm{cm})$, weights $(\mathrm{kg})$, body surface area and body mass index were the principal physical characteristics considered. ${ }^{1,2}$ Resting heart rate (RHR) was measured by allowing the subjects to take rest in a comfortable rest area (Dry bulb temp 21.6 \pm 3.1 , Wet Bulb 
temp $17.6 \pm 2.9$ and Relative humidity $67 \pm 8 \%$ ) for at least 30 minutes at the surface. The minimum heart rate obtained during this period was considered as the resting heart rate.Maximum heart rate $\left(\mathrm{HR}_{\max }\right)$ was estimated from age following the equation of American Heart Association. ${ }^{3}$ Heart rate reserve (HRR) was calculated as the difference between the maximal and resting heart rate of the subjects

Working heart rate (WHR) was measured by using the portable telemetric heart rate monitor - Sports Tester PE 3000 (Polar Electro, Finland) at a regular interval of $1 \mathrm{~min}$ during work. Recovery heart rate was measured in sitting posture at the end of work shift. This was obtained by counting the pulse during the last 30 seconds of each minute in the first, second and third minute of the recovery period, i.e. from $30 \mathrm{sec}$ to 1 minute after work stops, from $1 \frac{1}{2}-2$ minute and again from $2 \frac{1}{2}-3$ minute. These three recovery heart rates were designated as $\mathrm{P} 1$ ( $1^{\text {st }}$ recovery heart rate), P2 ( $2^{\text {nd }}$ recovery heart rate) and P3 ( $3^{\text {rd }}$ recovery heart rate).

Net cardiac cost (NCC) was obtained as the difference between WHR and resting heart rate and expressed in beats/ min. Relative cardiac cost (RCC) was found by expressing the NCC as the percentage of the heart rate reserve (HRR) of the subjects by using the following formula. $\mathrm{RCC}=\mathrm{NCC} /$ HRR * 100 .

To assess the thermal conditions, Wet Bulb Globe Temperature (WBGT) was worked out as an index of heat stress along with the effective temperature (ET).All the environmental readings were taken at regular intervals throughout the shift to get an average picture of the heat load throughout the shift. It was important to mention that each miner was studied on a single day while he was regularly involved in his assigned task and no instructions were given to control the work pace and methods. Studies were conducted during general shift between 08.00 to $16.00 \mathrm{hrs}$.

Descriptive statistics comprising mean, standard deviation and range were worked out for each set of data with standard SPSS version 10. Difference between means were tested by two-tailed $\mathrm{t}$ test with level of significance, á = 0.05 .

\section{Results}

\section{Physical and physiological characteristics}

Physical and physiological characteristics of the subjects exhibited that the mean age of dressers had been nearly 47 \pm 7.2 years with a body weight ranging from 48 to $64.5 \mathrm{~kg}$ (Table 1). The BMI of the workers $(21 \pm 2.7)$ showed that the subjects were typical of the average populations from eastern India. ${ }^{4}$ The average resting heart rate was found to be 67 beats / min and heart rate reserve depicts a range from 90 to 123 beats / $\mathrm{min}$.

Table 1: Physical and physiological characteristics of Dressers

\begin{tabular}{ll} 
Parameters & $(\mathbf{n}=\mathbf{8})$ \\
\hline Age $(\mathbf{y e a r})$ & $46.8 \pm 7.2(35-55)$ \\
Height $(\mathbf{c m})$ & $161.4 \pm 5.9(152-170)$ \\
Weight $\mathbf{( k g )}$ & $56.1 \pm 6.6(48-64.5)$ \\
Body Mass index $\left(\mathbf{k g} / \mathbf{~ m}^{2}\right)$ & $21.7 \pm 2.7(18.5-26.2)$ \\
Body Surface Area $\left(\mathbf{m}^{2}\right)$ & $1.58 \pm 0.1(1.46-1.71)$ \\
Resting heart rate $(\mathbf{b e a t s} / \mathbf{m i n})$ & $67 \pm 5.5(60-76)$ \\
Maximum heart rate (beats / $\mathbf{m i n})$ & $173.3 \pm 7.2(165-185)$ \\
Heart rate reserve (beats / min) & $106.3 \pm 12.4(90-123)$
\end{tabular}

\section{Description of activities}

The workers performed two spells of work per shift and two to three cycles of drilling per spell (Table 2). Maximum time was spent in dressing roofs and side walls of a coal face $(89 \%)$ and walking with dressing rod contributed little (11\%) in a single spell. Rest time or pause time observed between spells were due to some mandatory mining activities like "blasting" and "removal of fumes" etc and "loading", which were performed by other group of workers. Some jobs of stochastic nature (e.g.updation of ventilation which got deranged by blasting violence, derailment of tubs etc) also contribute to this pause time.

Beside the time spent in two spells of work including the pause time in between, a major portion of total shift time was spent in other activities like giving attendance and collecting equipments at the beginning of the work shift prior to their entry into the mine. Time was also spent for walking to and fro journeys to the actual site of coal extraction. It was seen through repeated studies that on an average 150 minutes were spent in these task

Table 2: Description of dressing tasks in underground coal mines

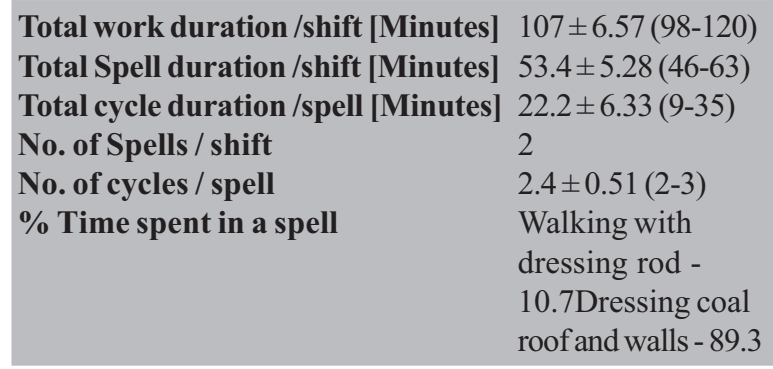

\section{Physiological strain of the dressers}

Mean working heart rate in second spell (122 beats/min) has significantly differed than that of the first spell (117 
Workload of dressers in coal mines

beats/min).NCC and RCC have also showed significant increased responses in second spell of work except Brouha's index.

Table 3: Physical workload in two spells amongst Dressers

For a more comprehensive analysis of the physical strain encountered by the dressers in two spells of work, the percentage of dressers exceeding recommended limits of different cardiac strain indices is assessed. The recommended ranges for WHR, limit for continuous work (LCW), RCC and NCC, Brouha's index were exceeded by all the miners in both spells of work (Table 4). However the percentage of the workers exceeding the limits for $50 \%$ RCC

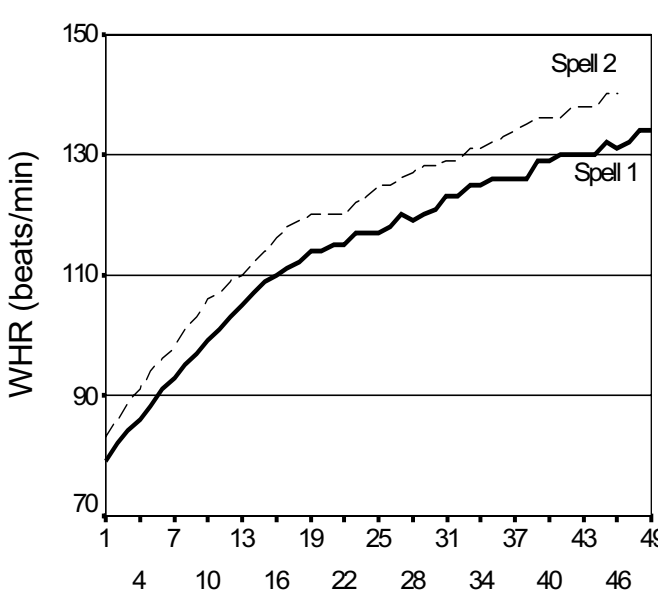
ringly found that inoticeably higher เQEd the $50 \%$ RCC

ing the recommended limits of physical strain

\begin{tabular}{|c|c|c|c|}
\hline \multirow{2}{*}{$\overline{\overline{1.05}}$} & \multirow[t]{2}{*}{ References } & \multicolumn{2}{|c|}{$(\mathrm{n}=8)$} \\
\hline & & Sp-1 & $\mathrm{Sp}-2$ \\
\hline$\sqrt{\mathrm{min}}$ & Saha et al (1969) & 100 & 100 \\
\hline \multirow[t]{3}{*}{ sting pulse } & Grandjean (1988) & 100 & 100 \\
\hline & Lablanch Combier and Ley (1984) & 100 & 100 \\
\hline & Do & 37.5 & 62.5 \\
\hline $\min$ & Do & 100 & 100 \\
\hline$/ \min$ & Brouha (1960) & 100 & 100 \\
\hline
\end{tabular}

The recordings of WHR per minute basis for the dressers in two different spells of work was assessed. As the working time for individual subject varies in different spells of work, the graph is constructed by plotting the mean heart rate / minute against the minimum working period of the workers which was ${ }^{8} 46$ minutes and 49 minutes respectively in spell 1 and spell 2 (Fig. 1).
Fig. 1: Distribution of WHR of dressers in Spell 1 and Spell2

The initial WHR of the dressers in both spells of work is within 80 to 90 beats / min and it shows a rising trend in general in both the spells The period of tachycardia is considered as WHR > 100 beats / min and it reaches within initial stages $\left(13^{\text {th }}\right.$ to $16^{\text {th }}$ minutes $)$ of the of respective work spells. A steep rise is observed at first period (from $1^{\text {st }}$ to $22^{\text {nd }}$ minute) when the heart rate rise from the level of 80-90 beats/min to 120 beats / min. After this a comparatively slower rate of increment of heart rate is observed throughout the rest of the work period. The maximum heart rate attained by the workers in the final minute of work was 134 beats/ min and 140 beats/min in spell 1 and spell 2, respectively.

Times spent at different RCC levels in two different spells by the dressers was analysed. The percentage of total spell time is plotted against RCC levels divided at regular intervals of $10 \%$. These figures provide a more proper clarification 
of physical strain involved in the task. In spell 1 the majority of the working time $(25.9 \%)$ is spent at a strain level of $51 \%$ $60 \%$ of RCC (Fig 2). In contrast to that the subjects in their second spell spend bulk of the work time (26\%) at a strain level of $61 \%-70 \%$ of RCC. The total spell time when the physical strain remains above $50 \%$ of RCC level has been found to be $49 \%$ and $61 \%$ in spell 1 and spell 2, respectively. It is also interesting to note that only in second spell workers has spent some of their working time at $81-90 \%$ of RCC level too.

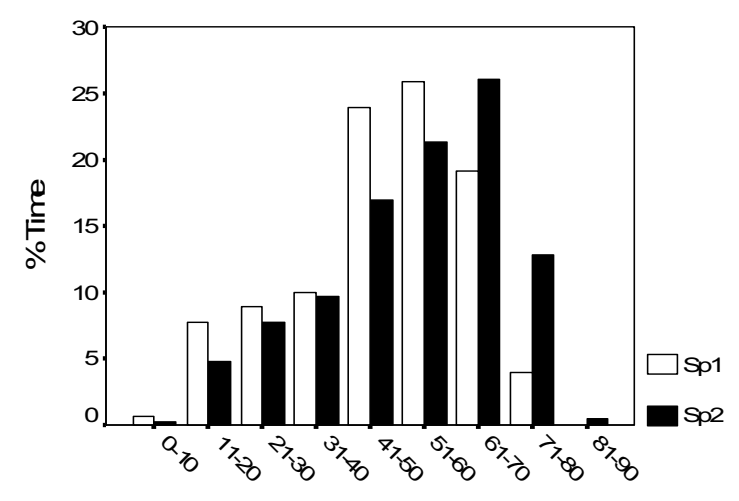

Relative cardiac cost

Fig. 2: Percent of time spent by dressers in Spell 1 and Spell2

The first minute of recovery for all the workers in first and second spell is 119 and 122 beats/min respectively (Fig. 3). In both the spells the rate of recovery is found to be very poor and this is well supported by the result since the Brouha's index fails to show any statistical significance.

The close proximity of dry bulb $\left(31.5 \pm 0.96^{\circ} \mathrm{C}\right)$ and wet bulb temperatures $\left(29.9 \pm 0.94{ }^{\circ} \mathrm{C}\right)$ at the worksites, reflecting

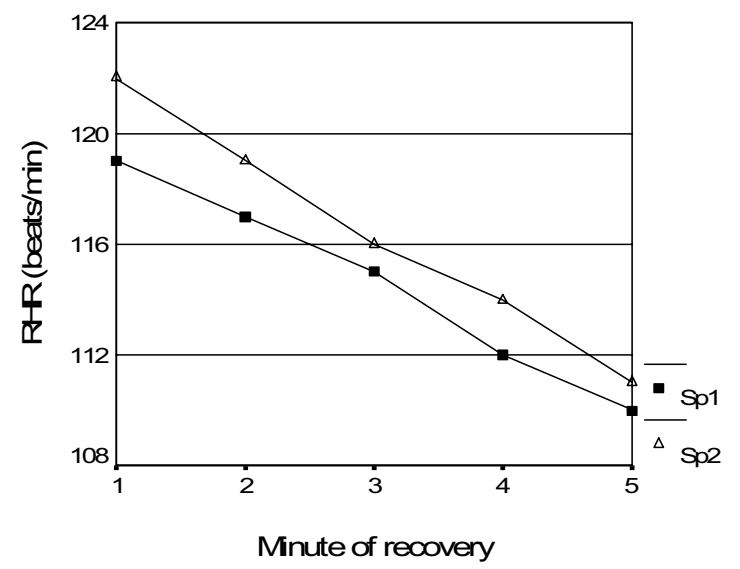

Fig. 3: Recovery trends of dressers after first and second spell of work high humidity (88\%) and conditions in which air velocity at working faces exhibits stagnancy $(0.21$ to $0.71 \mathrm{~m} / \mathrm{sec})$. The ET in different workplaces varied from $26.5-31.5^{\circ} \mathrm{C}$ with a mean temperature of $29.5^{\circ} \mathrm{C}( \pm 0.87)$ (Table 5). The mean natural wet bulb temperature was observed to be $30.5 \pm 1.02$ ${ }^{\circ} \mathrm{C}$ with wet bulb globe temperature values at the different working coalfaces ranging from $27.5-32.5^{\circ} \mathrm{C}$.

Table 5: Mean environmental heat load in the working sites

\begin{tabular}{|c|c|c|c|}
\hline Environmental parameters & Mean & SD & Range \\
\hline $\begin{array}{c}\text { Natural wet bulb } \\
\text { temperature }\left({ }^{\circ} \mathbf{C}\right)\end{array}$ & 30.5 & \pm 1.02 & $(27-32)$ \\
\hline $\begin{array}{c}\text { Dry bulb temperature }\left({ }^{\circ} \mathbf{C}\right) \\
\text { Wet bulb temperature }\left({ }^{\circ} \mathbf{C}\right)\end{array}$ & 31.5 & \pm 0.96 & $(28.5-33.5)$ \\
\hline Air velocity (m/sec) & 0.37 & \pm 0.12 & $(0.21-0.71)$ \\
\hline Humidity (\%) & 88 & \pm 3.5 & $(75-93)$ \\
\hline Effective Temperature $\left({ }^{\circ} \mathbf{C}\right)$ & 29.5 & \pm 0.87 & $(26.5-31.5)$ \\
\hline $\begin{array}{c}\text { Wet bulb globe } \\
\text { temperature }\left({ }^{\circ} \mathbf{C}\right)\end{array}$ & 30.7 & \pm 1.06 & $(27.5-32.5)$ \\
\hline
\end{tabular}

\section{Discussion}

The height and weight of the subjects are quite similar to the average populations from eastern India and from BMI values it appears that the subjects were not energy deficient. $^{4}$

The work load entailed by the dressers in the shift was evaluated in accordance with the heaviness scales based on different parameters like working heart rate, recovery heart rate and $\mathrm{NCC}^{5-7}$ Based on working heart rate and NCC criteria the workload in both spells of work appeared to be "heavy" in nature. However, in accordance with the recovery heart rate criteria applicable for Indian standard the workload appeared to be "very heavy" to "extremely heavy" in nature.

The dressing activity as observed in the work place involved a significant amount of static muscular effort since they have to hold the dressing rod maximally above and at the shoulder level to dress coal face; more often than not beside dressing the blasted area adequate amount of pushing force was also required to break the large layers of coal from the roof side as well as the walls. Furthermore, at times the work was done standing above the heaped coal where the workers experienced a great deal of difficulty in engaging their foot due to the chances of slippage and thereby facing a challenge of postural disequilibria. This pattern of work 
Workload of dressers in coal mines

where preponderance of static load was quite clear represented a non-steady work phases of escalating heart rates in both the spells and might have led to a very poor recovery of the workers after first spell of work as evident from the 'no-recovery' pattern for all the workers. ${ }^{8,9}$

It is quite obvious that the magnitude of physiological response will vary in conjunction with the task performed. Present study depicts similar results like the earlier observations where short burst of physical activity were riveted with low demand of tasks since a part of their working time dressers were involved in low demanding non specific activities performed in the pause time placed between arduous work spells. ${ }^{10,11}$ It is useful to mention that the rest pause in between spells was merely nonvolitional (ascribed to the time spent for blasting, loading of coal, updation of ventilation deranged by blasting violence, etc) and was a-periodically placed. So to have a comprehensive recovery they barely enjoy a complete rest period in between spells. These could have been the reasons towards formulating a cumulative stress amongst the workers in the second spell where the physiological responses were found to be significantly higher as compared to the $1^{\text {st }}$ spell. Moreover an elevation of initial heart rate at the beginning of second spell was a very good indicative of increased stress too. Basically recovery from such an increased strain was so poor that no significant difference was observed when the PDI's were considered after two spell of work.

It was also seen that most of the workers crossed their recommended levels of cardiac strain indices and it bears the fact that the activity placed a serious cardiovascular load on miners during working periods. The mean recovery heart rate pattern (figure 4) also exposed dissatisfied recovery for all the workers. The sustained and slow recovery after each spell of work substantiates to the insufficient capacity of the workers and their overexertion on the cardiovascular system ${ }^{12-13}$ and this could only worse older subjects in present scenario. The trend of recovery heart rate at the end of $1^{\text {st }}$ minute also indicated that the job would cause excessive cardiovascular strain if continued for the subjects. ${ }^{14}$

Heart rates as found in the present study showed higher values than that of Bulgarian open cast blasters, diggers and drillers (100-110 beats/ $\mathrm{min})^{15}$, Spanish underground coal face miners $(103-106.5 \text { beats } / \mathrm{min})^{16}$, Australian miners (101-103 beats/min $)^{10}$ and Indian underground coal mine trammers $(102-105$ beats $/ \mathrm{min}){ }^{17}$ but lower from native underground coal mine carriers $(124-133 \text { beats } / \mathrm{min})^{18}$ and shovellers (130-138 beats/min) ${ }^{19}$ and nearly comparable with the drillers (117-132 beats/min).$^{20}$ The higher level of RCC in dressers (44\%-58\%) can be explained from their significantly lower heart rate reserve level in relation to younger workers when compared with the Spanish underground miners $(32 \%)^{16}$ but lower from their native carrier $(50 \%-66 \%)$ and shoveller counterparts $(54 \%-65 \%) .{ }^{18,19}$ Interestingly the RCC values are almost within the same range when compared with native coal mine drillers $(44 \%-48 \%)$ of similar age. ${ }^{20}$ Disagreement with the overseas literatures might be due to the continuous observations of heart rates through out the work period extending for four to five work shifts along with recording of heart rates in the rest periods as well. The workload in the present findings was found to be higher in contrast to other non - mining tasks like Indian agriculture and inland fishing job ${ }^{21,22,23}$, British silviculture work ${ }^{24}$, Steel work ${ }^{25}$, and car assembly work as well. ${ }^{26}$

The existing ET in the worksites remained not only above the recommended value $\left(28.5^{\circ} \mathrm{C}\right)$ for heavy type of work as suggested by WHObut remained within hot zone according to the classification of environmental conditions for Indians. ${ }^{27,28}$ The mean WBGT also reflected that permissible limits for continuous work was well encroached as proposed by ACGIH. ${ }^{29}$ The heavy strain of the job associated with inadequate recovery of the workers can also be imparted to the prevailing thermal stress. ${ }^{9,30}$ Since ET remained over 27 ${ }^{\circ} \mathrm{C}$ actions should be taken to ward off the risks of heat strain ${ }^{31,32}$ as a high level of physical effort could impose deleterious impact on the miners. ${ }^{33}$

\section{Conclusions}

It is found that though the average duration of work in underground dressing job is far less than usual industrial sectors yet it can not be undermined. The existing work pattern showed cardiovascular stress with poor recovery of the Indian miners which resulted typically from the involvement of a compromise between one's capabilities and his job requirement irrespective of ages, which may in some circumstances create vital and adverse implications on worker's health issues.

\section{Acknowledgements}

The authors are thankful for the grant provided by the University Grants Commission, India for the implementation of this study. Moreover we are grateful to the General Manager of Kenda Area (West Bengal), colliery managers and assistant managers of different underground units of the area who rendered all possible facilities for the successful completion of the study. The authors also put across their special thanks to the dressers who generously cooperated and spared their valuable time for the study. 


\section{Conflict of Interest: No}

\section{References}

1. DuBois D, DuBois EF. Clinical Calorimeter X. A formula to estimate the approximate surface area if height and weight be known. Arch.Intern.Med. 1916:17:863.

2. Key A, Fidanza F, Karnoven M J. Indices of relative weight and obesity. J Chronic Dis. 1972;25:329-43.

3. American Heart Association, Committee of exercise. Exercise testing and training of apparently healthy individual: A handbook of physician. New York: American Heart Association; 1972.

4. Naidu AN, Rao NP. Body mass index: a measure of the nutritional status in Indian populations. Eur J Clin Nutr. 1994; 48(Supp 1):131-40.

5. Åstrand PO, Rodhal K. Text book of work physiology. New York: Mc Graw Hill; 1986.

6. Samanta A. Recovery heart rate as a tool for the assessment of work stress. Ind J Physiol Allied Sc. 1984;38:123-8.

7. Chamoux A, Borel AM, Catilina P. Pour la standardization d' unefrequence cardiaque de repos. Arch Mal Prof. 1985;46:241-50.

8. Yang L, Lin Y, Liu W, Liu J, Liu H. Load assessment of the static posture and weight holding in terms of pulmonary ventilation and heart rate. J Tongji Med Univ. 1997; 17(3):156-9.

9. Brouha L. Evaluation of the physiological requirements of jobs. In: Physiology in Industry: Evaluation of Industrial stress by the physiological reaction of the workers. Paragon press;1960. p. 82-108.

10. Brake DJ, Bates GP. Fatigue in industrial workers under thermal stress on extended shift lengths. Occp Med. 2001;51:7:456-63.

11. Montoliu MA, Gonzalez V, Palenciano L. Cardiac frequency throughout a working shift in coal miners. Ergonomics. 1995:38:(6)1250-63.

12. Brouha L. Physiology in Industry. $2^{\text {nd }}$ ed. Oxford: Pergamon Press; 1967.

13. Bernard TE, Kenney WL. Rationale for a personal monitor for heat strain. Am Ind Hyg Assoc J. 1994;55:505-14.

14. Chengalur SN, Rudgers SH, Bernard TE. Kodak's Ergonomic Design for People at Work. 2nd ed. New Jersy: John Wiley and Sonsy; 2004.
15. Mincheva L, Khadzhiolova I, Deianov Kh. An occupational physiology study at the Asarel mining and milling works: The evaluation of the workload in the basic jobs in open-pit mines. Probl Khig. 1995:20: $35-47$.

16. Palenciano L, Gonzalez V, Santullano LA, Montoliu MA. Cardiac frequency in miners recorded during four to five work shifts. Eur J Appl Physiol Occup Physiol. 1996;73(3-4):369-75.

17. Dey NC, Samanta A, Saha R. A study of the workload of underground trammers in the Raniganj coalfield area of West Bengal, India. Int J Occup Safety Ergon. 2006;12 (4):399-407.

18. Saha R, Dey NC, Samanta A, Biswas R. A comparison of physiological strain of carriers in underground manual coal mines in India. International Journal of Occupational and Environmental Health. 2008;14(3):210-7.

19. Dey NC, Samanta A, Saha R. Cardiovascular load assessment of coal mine shovelers in West Bengal, India: A comparison between middle age groups. J Hum Ergol. 2006; 35:41-4.

20. Saha R, Dey NC, Samanta A, Biswas R. A comparison of cardiac strain among drillers of two different age groups in underground manual coal mines in India. Journal of Occupational Health. 2008;50(6):512-20.

21. Ghosh S, Kar SK, Sau SK, Banerjee S, Dhara P. Cardiovascular stress of women engaged in different paddy cultivation activities. Ind J Physiol Allied Sc. 2003; 57(3):74-82.

22. Biswas R, Samanta A, Chatterjee S. Physiological cost of pond fishing. Ind J Physiol Allied Sc. 2005;59(3): 58-68.

23. Biswas R, Samanta A. Assessment of physiological strain in inland fishing activity. Ind J Occup Environ Med. 2006;10(1):19-23.

24. Trites DG, Robinson DG, Banister EW. Cardiovascular and muscular strain during a tree planting season among British - Columbia silviculture workers. Ergonomics. 1993;36:935-49.

25. Vitalis A, Pournaras ND, Jeffrey GB, Tsagarakis G, Monastiriotis G, Kavvadias S. Heart rate strain indices in Greek steelworkers. Ergonomics. 1994;37:845-50.

26. Goldsmith R, O', Brien C, Tn GLE, Smith WS, Dixon M. The cost of work on a vehicle assembly line. Ergonomics. 1978;21:315-23. 
Workload of dressers in coal mines

27. WHO. Health factors in working under conditions of heat stress. Geneva 412: WHO Tech. Rep. Series; 1969.

28. Mookherjee GC, Sharma RN. A report on environmental 'comfort zone' in tropics. J Sci Ind Res. 1953;6:283-7.

29. Threshold Limit Values for Chemical Substances and Physical Agents and Biological Exposure Indices. TLVs and BEIs. Cincinnati, Ohio: ACGIH 2001:171-2.

30. Fuller FH, Smith PE. Evaluation of heat stress in a hot workshop by physiological Measurement. Amer Ind Hyg Assoc. 1982;42:32-7.

31. Hanson MA, Cowie HA, George JPK, Graham MK, Graveling RA, Hutchison PA. Physiological Monitoring of Heat Stress in UK Coal Mines. IOM Research ReportTM00/05.2000.

32. Pickering AJ, Tuck MA. Heat: sources, evaluation, determination of heat stress, and heat stress treatment. Mining Technology, Trans. I. Min E. 1997:79(910): 147-56.

33. Kulagowska E. Physical cost of working under conditions of thermal load. Med Pr. 1997;48(3):265-71. 